\title{
A MULTILAMINATE MODEL WITH DESTRUCTURATION CONSIDERING ANISOTROPIC STRENGTH AND ANISOTROPIC BONDING
}

\author{
Vahid Galavi ${ }^{\text {i) }}$ and Helmut F. Schweiger ${ }^{\text {ii) }}$
}

\begin{abstract}
Many constitutive models have been developed to describe the behaviour of soils, but only more recently a limited number of them have paid attention to include effects of structure and consequently destructuration due to volumetric and/or deviatoric straining. Most of them consider isotropic behaviour for strength and structure of soil. In this paper a multilaminate type of constitutive model is presented in which anisotropic strength and anisotropic structure are taken into account. According to the mathematical formulation of the multilaminate framework, this kind of model is capable of taking into account induced anisotropy intrinsically. Inherent anisotropy can be introduced to the model by varying the model properties over sampling planes using a so-called microstructure tensor. Only mechanical destructuration, namely degradation of structure with deformation is considered in this paper. The proposed model is capable to consider anisotropy in bonding and preconsolidation pressure as well as inherent anisotropy in strength thus the hardening of the yield surface and strength parameters can be considered direction dependent. In this paper the drained and undrained behaviour of natural clays is simulated and the effect of different assumptions with respect to structure degradation and anisotropy is evaluated.
\end{abstract}

Key words: constitutive modelling, destructuration, multilaminate model (IGC: D6/E1/T6)

\section{INTRODUCTION}

Mechanical behaviour of natural soils is affected by their initial structure (usually with inherent anisotropy) and behaves differently from reconstituted or remoulded soils. The effects of structure on the behaviour of soils have been reported for almost all weak rocks (e.g., Elliot and Brown, 1985) and soils, such as clays (soft, stiff or shales), granular soils, and deep-ocean sediments (e.g., Burland, 1990; Leroueil and Vaughan, 1990; Cotecchia and Chandler, 1997, 2000; Baudet and Ho, 2004). Various models have been recently developed to consider effects of destructuration (e.g., Rouainia and Muir Wood, 2000; Kavvadas and Amorosi, 2000; Koskinen et al., 2002; Liu and Carter, 2002; Nova et al., 2003; Baudet and Stallebrass, 2004; Cudny and Vermeer, 2004), but none of them consider both destructuration and strength anisotropy together.

One class of constitutive models, in which various aspects of the mechanical behaviour of soils can be implemented, is the multilaminate model introduced for soils by Pande and Sharma (1983). In the multilaminate framework, the overall deformation of a soil body is obtained from deformation on so-called sampling or contact planes and plastic strains developed independently on planes. Thus multilaminate models are able to take into account induced anisotropy intrinsically. Inherent anisotropy, which is a result of having different strength in different directions, can also be introduced in a straightforward manner by varying model parameters over the sampling planes. In this study a micro-structure tensor proposed by Pietruszczak and Mroz (2000) is utilised for spatial distribution of direction dependent parameters over the sampling planes. As shown by Schweiger et al. (2009) the proposed model is able to simulate induced anisotropic behaviour of natural clays observed in laboratory experimental tests. Here, it is attempted to show how destructuration together with inherent anisotropy can be considered for modelling the behaviour of normally or slightly overconsolidated natural clays within the multilaminate framework.

\section{EXPERIMENTAL BACKGROUND}

The mechanical behaviour of natural soils depends on the initial structure of the soil in its natural state. The term structure is defined by Lambe and Whitman (1969), and Cotecchia and Chandler (1997) as the combination of fabric, the arrangement of the soil component particles, and bonding, those interparticle forces which are not of a purely frictional nature. The initial state of the structure of a soil is called intact state. The structure of an intact

i) Plaxis B. V., The Netherlands (formerly Graz University of Technology, Austria).

ii) Computational Geotechnics Group, Institute for Soil Mechanics and Foundation Engineering, Graz University of Technology, Austria (helmut.schweiger@tugraz.at).

The manuscript for this paper was received for review on February 15, 2008; approved on November $27,2008$.

Written discussions on this paper should be submitted before January 1, 2010 to the Japanese Geotechnical Society, 4-38-2, Sengoku, Bunkyoku, Tokyo 112-0011, Japan. Upon request the closing date may be extended one month. 
soil is degraded by some factors such as weathering, chemical degradation and mechanical degradation. Leroueil et al. (1979) called the degradation of structure destructuration. The mechanical destructuration results from volumetric and/or shearing deformation. The bonds between particles are broken during destructuration and therefore destructuration may lead to high sensitive behaviour of clays.

In addition to the above definitions, Burland (1990) defined an additional state, namely the reconstituted state. He designated the term intrinsic to describe the properties of clays which have been reconstituted at a water content of between $w_{\mathrm{L}}$ and $1.5 w_{\mathrm{L}}$ (preferably $1.25 w_{\mathrm{L}}$ ) without air drying or oven drying, and then consolidated preferably in one dimensional consolidation. The properties of such soils are inherent to the material and are independent of their natural state (Burland et al., 1996). In this study, following the suggestion of Burland (1990), the intrinsic properties are denoted by an asterisk (*) attached to the relevant symbol.

To investigate the mechanical behaviour of natural soils significant experimental research has been conducted in the past two decades in order to gain a better understanding of compressibility and shear strength of natural soils (e.g., Burland, 1990; Burland et al., 1996; Leroueil and Vaughan, 1990; Cotecchia and Chandler, 1997, 2000; Amorosi and Rampello, 1998). It follows from their work that the structure of a natural soil collapses with increasing volumetric and/or shear deformations such that the structure level of the natural soil approaches the structure level of the reconstituted one after large plastic deformation. These changes of structure level depend on the applied stress level (Amorosi and Rampello, 1998).

To identify mechanical properties of natural soils, the behaviour of reconstituted soil is first determined followed by an attempt to find a relation between the properties of the reconstituted soil and the natural one. It is postulated that the differences between intrinsic and natural properties are due to the structure of the natural soil (Burland, 1990; Burland et al., 1996).

The main effects of structure on the mechanical behaviour of the natural soils can be summarised as: The limit state curve of natural soil is above of the limit state curve of destructured soil. Therefore the peak strength envelope of intact soil lies above the envelope of destructured soil and the preconsolidation pressure of a structured soil, obtained from one-dimensional compression test, may be higher than the preconsolidation pressure of the destructured soil (e.g., Burland, 1990; Burland et al., 1996; Leroueil and Vaughan, 1990; Saihi et al., 2002). At the limit state, bonds are still present but after large deformations (critical state) most of the bonds are broken. The critical state of structured soils is inside the limit state curve while it coincides with limit state curves for destructured soils (Saihi et al., 2002; Burland et al., 1996; Cotecchia and Chandler, 1997).

\section{MULTILAMINATE FRAMEWORK}

Generally, the multilaminate framework establishes a simplified relationship between the micro-scale mechanical behaviour of a material and the macro-scale one. This concept is based on the slip theory which dates back to Taylor (1938). Within this framework the global behaviour of a material is obtained from material properties on slip planes. According to this framework, the behaviour of soils can be simplified by assuming the soil body to be a combination of solid particles and a number of imaginary sliding planes (or sampling planes) which are oriented in space according to the integration rule used. The overall plastic deformation of a soil body is then a result of plastic movement along these planes under current effective stresses, calculated from the global stress tensor, acting on these planes. The total deformation of the soil is therefore equal to elastic deformation of solid particles and plastic deformation obtained from deformation on the planes. To calculate the global plastic strain, numerical integration is applied and the accuracy of the numerical integration depends on the number, orientation and distribution of sampling planes (Eq. (1)).

$$
\int_{S} h(x, y, z) d S \approx \sum_{\mathrm{i}=1}^{n_{\mathrm{SP}}} h\left(x_{\mathrm{i}}, y_{\mathrm{i}}, z_{\mathrm{i}}\right) w_{\mathrm{i}}
$$

$S$ is the surface of the unit sphere, $n_{\mathrm{SP}}$ is the number of sampling planes on which the summation is taken and $h(x, y, z)$ is a continuous function. $x_{\mathrm{i}}, y_{\mathrm{i}}$ and $z_{\mathrm{i}}$ are the direction cosines of the normal vector to the sampling plane $i$ and $w_{\mathrm{i}}$ is weighting coefficient of the sampling plane $i$.

Number and the distribution of sampling planes on the sphere are governed by the integration rule. In a symmetrical case, for each two points on the sphere one plane is specified, therefore, the integration can be carried out on a hemisphere rather than a sphere and the corresponding weighting coefficients are doubled (Bažant and Oh, 1985), which reduces the computational efforts. All calculations presented in this study are based on $2 \times 33$ symmetric sampling planes keeping a balance between computational effort and calculation accuracy.

\section{MATHEMATICAL FORMULATION}

According to the additivity postulate of the theory of plasticity, the overall deformation of a soil mass is the summation of elastic and plastic deformations. Therefore, the total strain increment $\mathbf{d} \boldsymbol{\varepsilon}$ consists of the elastic strain increment $\mathbf{d} \varepsilon^{\mathrm{e}}$ and the plastic strain increment $\mathbf{d} \varepsilon^{\mathrm{p}}$ :

$$
\mathbf{d} \varepsilon=\mathbf{d} \varepsilon^{\mathrm{e}}+\mathbf{d} \varepsilon^{\mathrm{p}}
$$

The elastic strain increment $\mathbf{d} \boldsymbol{\varepsilon}^{\mathrm{e}}$ depends on the effective stress increment $\mathbf{d} \boldsymbol{\sigma}^{\prime}$ :

$$
\mathbf{d} \varepsilon^{\mathrm{e}}=\left(D^{\mathrm{e}}\right)^{-1} \mathbf{d} \sigma^{\prime}
$$

where $\mathbf{D}^{\mathrm{e}}$ represents the elastic stiffness tensor of the soil body. In this study, isotropic elasticity is assumed for simplicity and the elastic strains are obtained from the 


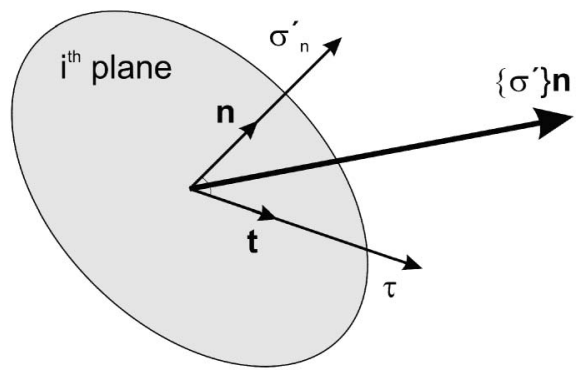

Fig. 1. Effective stresses on the $i^{\text {th }}$ sampling plane

global stiffness tensor of the soil body. A multilaminate model considering also elastic strains on sampling planes is presented by Scharinger (2007).

Within the multilaminate framework, yield and plastic potential functions are specified independently on the sampling planes. The yield function for the $i^{\text {th }}$ sampling plane can be written as a function of the micro level effective stress $\sigma_{\mathrm{i}}^{\prime}$ and the hardening (or softening) parameter which is a function of the accumulated plastic strain $\varepsilon_{i}^{\mathrm{p}}$ on the respective plane.

$$
f_{\mathrm{i}}=f_{\mathrm{i}}\left(\sigma_{\mathrm{i}}^{\prime}, \varepsilon_{\mathrm{i}}^{\mathrm{p}}\right)
$$

The micro level effective stress $\sigma_{\mathrm{i}}^{\prime}$ on each sampling plane (Fig. 1) is obtained by means of:

$$
\boldsymbol{\sigma}_{\mathrm{i}}^{\prime}=\left[\begin{array}{c}
\sigma_{\mathrm{n}}^{\prime} \\
\tau
\end{array}\right]=\left[\begin{array}{c}
\sigma^{\prime} \mathbf{n}_{\mathrm{i}} \cdot \mathbf{n}_{\mathrm{i}} \\
\left\|\sigma^{\prime} \mathbf{n}_{\mathrm{i}}-\left(\boldsymbol{\sigma}^{\prime} \mathbf{n}_{\mathrm{i}} \cdot \mathbf{n}_{\mathrm{i}}\right) \mathbf{n}_{\mathrm{i}}\right\|
\end{array}\right]
$$

$\boldsymbol{\sigma}^{\prime}$ is the effective stress tensor and $\mathbf{n}_{\mathrm{i}}$ is the normal unit vector of plane $i$. Note that in Eq. (5), subscript $i$ does not denote the summation notation over $i$. The increment of plastic strain $\mathbf{d} \varepsilon_{\mathrm{i}}^{\mathrm{p}}$ of the $i^{\text {th }}$ sampling plane is given by:

$$
\mathbf{d} \varepsilon_{\mathrm{i}}^{\mathrm{p}}=d \Lambda_{\mathrm{i}} \frac{\partial g_{\mathrm{i}}}{\partial \sigma_{\mathrm{i}}^{\prime}}
$$

in which $d \Lambda_{\mathrm{i}}$ is the increment of the micro level plastic multiplier and $g_{\mathrm{i}}$ is the micro level plastic potential function. The increment of micro level plastic strain $\mathbf{d} \varepsilon_{\mathrm{i}}^{\mathrm{p}}$ is only calculated for sampling planes in which the yield function is zero $\left(f_{\mathrm{i}}=0\right)$.

To obtain the global plastic strain increment $\mathbf{d} \varepsilon^{\mathrm{p}}$, the contributions from all sampling planes have to be taken into account by transformation of the micro level plastic strain increment $\mathbf{d} \varepsilon_{\mathrm{i}}^{\mathrm{p}}$ and the integration over the surface of the unit sphere:

$$
\mathbf{d} \varepsilon^{\mathrm{p}}=\int_{S} \mathbf{T}_{\mathrm{i}} \mathbf{d} \varepsilon_{\mathrm{i}}^{\mathrm{p}} d S=\int_{S} d \Lambda_{\mathrm{i}} \mathbf{T}_{\mathrm{i}} \frac{\partial g_{\mathrm{i}}}{\partial \sigma_{\mathrm{i}}^{\prime}} d S
$$

$S$ denotes the surface of the unit sphere and $\mathbf{T}_{\mathrm{i}}$ is the transformation matrix of the sampling plane $i$. As mentioned before the above integration can be numerically approximated by the following summation:

$$
\mathbf{d} \varepsilon^{\mathrm{p}}=\sum_{\mathrm{i}=1}^{n_{\mathrm{sp}}} \mathbf{T}_{\mathrm{i}} \mathbf{d} \varepsilon_{\mathrm{i}}^{\mathrm{p}} w_{\mathrm{i}}=\sum_{\mathrm{i}=1}^{n_{\mathrm{SP}}} d \Lambda_{\mathrm{i}} \mathbf{T}_{\mathrm{i}} \frac{\partial g_{\mathrm{i}}}{\partial \sigma_{\mathrm{i}}^{\prime}} w_{\mathrm{i}}
$$

\section{DESCRIPTION OF THE MODEL}

In this section the basic formulation of the multilaminate model, which has been developed and implemented into PLAXIS (Brinkgreve et al., 2006) by Wiltafsky (2003) via the user-defined soil model option, is briefly summarized before the enhancements made to incorporate destructuration and inherent anisotropy are discussed. The multilaminate model is an elasto-plastic model which is described for one sampling plane but the same formulation is applied for all sampling planes. As described in the previous section, the global behaviour is obtained by the weighted summation of all contributions from all sampling planes. Thus, all formulations are given on the level of a sampling plane and therefore instead of defining a global yield surface, yield curves (on each sampling plane) are defined. The evolution of the yield curves on each sampling plane is a function of the accumulated plastic strains on the respective plane. Before discussing destructuration and anisotropy the basic formulation of the model, which serves as a starting point, is briefly summarized. Details can be found in Wiltafsky (2003). It should be noted that the mechanical sign convention is used in this paper, i.e., tensile stresses and strains are positive.

\section{YIELD FUNCTION AND HARDENING LAW}

The model includes both deviatoric and volumetric hardening. The yield curve of the model on each sampling plane consists of three parts $f_{\mathrm{d}}, f_{\mathrm{v}}$ and $f_{\mathrm{t}}$ called the deviatoric, the volumetric and the tension parts of the yield curve, respectively. Figure 2 represents the yield curve of the multilaminate model on a representative sampling plane. The yield function $f_{\mathrm{d}}$ (Eq. (9)) is an extended Mohr-Coulomb criterion by introducing the mobilised friction angle $\varphi_{\text {mob }}^{\prime}$.

$$
\begin{aligned}
& f_{\mathrm{d}}=\tau+\sigma_{\mathrm{n}}^{\prime} \cdot \tan \varphi_{\mathrm{mob}}^{\prime}-\frac{c^{\prime} \cdot \tan \varphi_{\mathrm{mob}}^{\prime}}{\tan \varphi_{\text {peak }}^{\prime}}=0 \\
& \tan \varphi_{\mathrm{mob}}^{\prime}=\tan \varphi_{\mathrm{i}}^{\prime}+\left(\tan \varphi_{\text {mod }}^{\prime}-\tan \varphi_{\mathrm{i}}^{\prime}\right) \cdot \frac{\varepsilon_{\gamma, \mathrm{d}}^{\mathrm{p}}}{\varepsilon_{\gamma, \mathrm{d}}^{\mathrm{p}}+A_{\text {mat }}}
\end{aligned}
$$

with

$$
\tan \varphi_{\text {mod }}^{\prime}=\frac{\tan \varphi_{\text {peak }}^{\prime}}{R_{\mathrm{f}}}
$$

$\varphi_{\mathrm{i}}^{\prime}, \varphi_{\text {peak }}^{\prime}$ and $\varphi_{\text {mod }}^{\prime}$ are initial, ultimate and modified effective friction angles respectively. The parameter $R_{\mathrm{f}}$, which is called failure ratio, is utilized to limit the hyperbolic curve (Eq. (10)) and is less than 1. The rate of deviatoric hardening is controlled by the parameter $A_{\text {mat }}$, which can be determined by calibration against triaxial test data. Larger values for $A_{\text {mat }}$ result in a slower mobilization of the friction angle with larger plastic shear strains. Therefore, the peak strength is reached at a higher shear strain. Mobilization of the friction angle is controlled by the accumulated deviatoric strain component $\varepsilon_{\gamma, \mathrm{d}}^{\mathrm{p}}$ obtained from the deviatoric part of the yield curve on each sampling plane. The second part of the yield curve is de- 


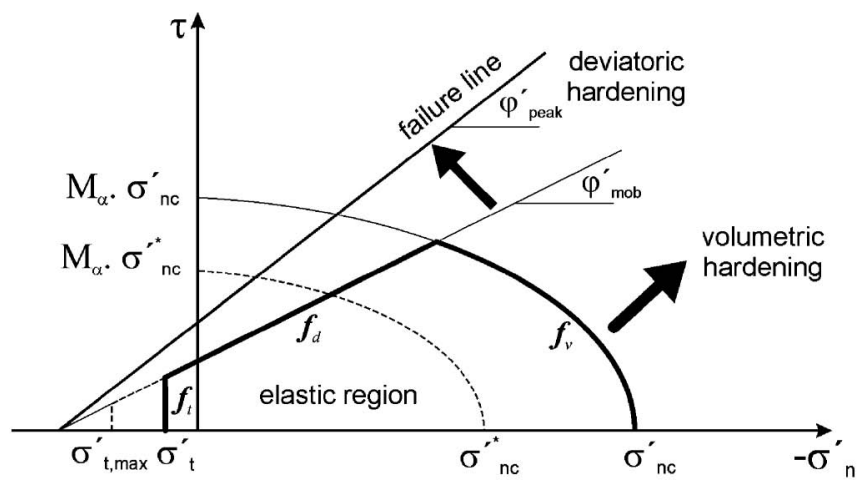

Fig. 2. The yield curve of the model on each sampling plane

scribed by the function $f_{\mathrm{v}}$ (Eq. (11)), which is an elliptically shaped function which expands during volumetric hardening with increasing accumulated plastic normal strain $\varepsilon_{\mathrm{n}, \mathrm{v}}^{\mathrm{p}}$ obtained from the volumetric part of the yield curve. $\sigma_{\mathrm{nc}}^{\prime}$ is the effective preconsolidation stress state of natural clay resulting from the loading history on the respective sampling plane. $M_{\alpha}$ is a parameter which governs shape of the volumetric part of the yield function.

$$
f_{\mathrm{v}}=\frac{\sigma_{\mathrm{n}}^{\prime 2}}{\sigma_{\mathrm{nc}}^{\prime 2}}+\frac{\tau^{2}}{\left(M_{\alpha} \cdot \sigma_{\mathrm{nc}}^{\prime}\right)^{2}}-1=0
$$

The relationship for the expansion of the volumetric part of the yield function $f_{\mathrm{v}}$ is given by Eq. (12). $\sigma_{\mathrm{nc}}^{\prime *}$ and $\sigma_{\mathrm{nc}, \mathrm{i}}^{\prime *}$ denote the actual and the initial effective preconsolidation normal stresses of the destructured clay. The actual effective preconsolidation normal stress of structured clay $\sigma_{\mathrm{nc}}^{\prime}$ is a function of $\sigma_{\mathrm{nc}}^{\prime *}$ and the current amount of structure of soil which will be discussed later. Following the notation of Burland (1990) $\lambda^{*}$ and $\kappa^{*}$ denote the slope of the normal compression line and the slope of the unloadingreloading line in the $\ln p^{\prime}-e$ diagram of the reconstituted clay, respectively.

$$
\sigma_{\mathrm{nc}}^{*}=\sigma_{\mathrm{nc}, \mathrm{i}}^{* *} \cdot e^{-K \cdot \varepsilon_{\mathrm{n}, \mathrm{v}}^{\mathrm{v}}}, \quad K=\frac{1+e}{\lambda^{*}-\kappa^{*}}
$$

The third part of the yield curve $f_{\mathrm{t}}$ is a tension cut-off criterion (Eq. (13)).

$$
f_{\mathrm{t}}=\sigma_{\mathrm{n}}^{\prime}-\sigma_{\mathrm{t}}^{\prime}=0
$$

\section{PLASTIC FLOW}

In this model, a non-associated flow rule is assumed for $f_{\mathrm{d}}$ and an associated flow rule for $f_{\mathrm{v}}$ and $f_{\mathrm{t}}$. The plastic potential function of the deviatoric yield curve is defined by;

$$
g_{\mathrm{d}}=\tau+\sigma_{\mathrm{n}}^{\prime} \cdot \tan \psi_{\mathrm{m}}
$$

Where

$$
\sin \psi_{\mathrm{m}}=\left(\frac{\sin \varphi_{\mathrm{m}}^{\prime}-\sin \varphi_{\mathrm{cv}}^{\prime}}{1-\sin \varphi_{\mathrm{m}}^{\prime} \cdot \sin \varphi_{\mathrm{cv}}^{\prime}}\right) \cdot\left(\frac{\sin \varphi_{\mathrm{m}}^{\prime}}{\sin \varphi_{\text {peak }}^{\prime}}\right)^{\mathrm{p}}
$$

with

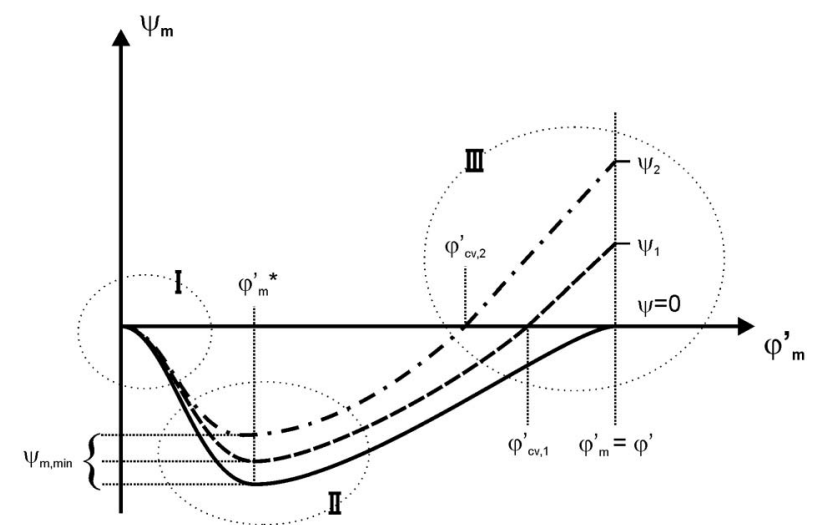

Fig. 3. Illustration of flow rule for deviatoric yield surface (Scharinger, 2007)

$$
\sin \varphi_{\mathrm{cv}}^{\prime}=\frac{\sin \varphi_{\text {peak }}^{\prime}-\sin \psi}{1-\sin \varphi_{\text {peak }}^{\prime} \cdot \sin \psi}
$$

This formulation corresponds to the stress dilatancy theory proposed by Rowe (1962) incorporating the modification by Søreide et al. (2002). As Scharinger (2007) showed, the modified version of the stress-dilatancy of Rowe (Søreide et al., 2002) reduces contractive behaviour at low mobilized friction angle, but still produces large and unrealistic excess pore pressures under undrained conditions when used with the multilaminate model. Therefore Scharinger (2007) developed a new formulation to improve the prediction under undrained conditions which is employed here. Figure 3 illustrates the proposed relationship between the mobilised friction angle $\varphi_{\mathrm{m}}^{\prime}$ and the mobilised dilation angle $\psi_{\mathrm{m}}$ whereas cubical functions are used in sections I and II as described in detail in Scharinger (2007). A linear function is used for the remaining part (section III in Fig. 3). The initial slope of the curve at $\varphi_{\text {mob }}^{\prime}=0$ is kept at zero. The two required input parameters are $\varphi_{\mathrm{m}}^{\prime *}$ and $\psi_{\mathrm{m} \text {,min }} \varphi_{\mathrm{m}}^{\prime *}$ is the mobilised friction angle defining $\psi_{\mathrm{m} \text {,min }}$ (negative, i.e., representing maximum contractancy). Both parameters have to be obtained by matching undrained triaxial test data (Scharinger, 2007).

\section{DEGRADATION OF STRUCTURE}

One effect of structure is that the limit state surface of the natural soil is above the limit state surface of the corresponding reconstituted soil. Thus, to simulate the degradation of structure the yield surface (or bounding surface) is considered larger than the yield surface (or bounding surface) of the corresponding reconstituted soil. The intact yield surface becomes smaller with increasing plastic strain such that after a large plastic strain these two surfaces coincide.

From experimental tests it is evident that both volumetric and shear strains influence the degradation of structure, because destructuration occurs in both compression and shearing. However, it is difficult to separate the influence of these two strains and therefore constitutive 
models presented in the literature differ in this respect. For example Liu and Carter (2002) and Cudny and Vermeer (2004) used only plastic volumetric strain whereas others (e.g., Gens and Nova, 1993; Rouainia and Muir Wood, 2000; Kavvadas and Amorosi, 2000; Koskinen et al., 2002; Liu and Carter, 2002; Nova et al., 2003; Baudet and Stallebrass, 2004) used both of them. In this work the damage strain $\varepsilon_{\mathrm{di}}$ on each sampling plane is defined as:

$$
\varepsilon_{\mathrm{di}}=\left(1-A_{\mathrm{d}}\right) \varepsilon_{\mathrm{n}}^{\mathrm{p}}+A_{\mathrm{d}} \varepsilon_{\gamma}^{\mathrm{p}}
$$

Where $\varepsilon_{\mathrm{n}}^{\mathrm{p}}$ and $\varepsilon_{\gamma}^{\mathrm{p}}$ are the summation of absolute values of all plastic strains on each sampling plane as follows:

$$
\begin{aligned}
& \varepsilon_{\mathrm{n}}^{\mathrm{p}}=\left|\varepsilon_{\mathrm{n}, \mathrm{v}}^{\mathrm{p}}\right|+\left|\varepsilon_{\mathrm{n}, \mathrm{d}}^{\mathrm{p}}\right|+\left|\varepsilon_{\mathrm{n}, \mathrm{t}}^{\mathrm{p}}\right| \\
& \varepsilon_{\gamma}^{\mathrm{p}}=\left|\varepsilon_{\gamma, \mathrm{v}}^{\mathrm{p}}\right|+\left|\varepsilon_{\gamma, \mathrm{d}}^{\mathrm{p}}\right|+\left|\varepsilon_{\gamma, \mathrm{t}}^{\mathrm{p}}\right|
\end{aligned}
$$

In Eqs. (17) and (18) it is assumed that the plastic strains obtained from the volumetric, deviatoric, and tension parts have the same influence on the degradation. $A_{\mathrm{d}}$ is a non-dimensional scaling parameter to control relative proportion of distortional and volumetric destructuration. It can be seen that for $A_{\mathrm{d}}=0$ the destructuration is entirely volumetric, whilst for $A_{\mathrm{d}}=1$ the destructuration is entirely distortional.

\section{DESTRUCTURATION LAW}

The normalized decrement of bonding with respect to initial bonding, which is assumed to be the bonding at gross yield (the point of starting destructuration), should be related to the increment of the damage strain $\varepsilon_{\mathrm{di}}$ defined by Eq. (16), because by increasing the damage strain, the degree of structure must decrease. This can be formulated as follows:

$$
\frac{d b}{b}=-h_{\mathrm{v}} \cdot d \varepsilon_{\mathrm{di}}
$$

where $h_{\mathrm{v}}$ is a non-dimensional parameter to control rate of destructuration with the damage strain $\varepsilon_{\mathrm{di}}$, and $b$ is a parameter to determine the amount of bonding. By integrating Eq. (19) and by introducing the amount of bonding at large plastic deformation (for stable structure), the amount of bonding at the damage strain $\varepsilon_{\mathrm{di}}$ yields:

$$
b=b_{\text {ult }}+\left(b_{\mathrm{i}}-b_{\text {ult }}\right) \exp \left(-h_{\mathrm{v}} \varepsilon_{\mathrm{di}}\right)
$$

where $b_{\mathrm{i}}$ is the initial amount of bonding on the respective sampling plane, which is assumed to be the bonding at gross yield. $b_{\text {ult }}$ is the ultimate value of bonding representing stable elements of structure. It follows from Eq. (20) that the amount of bonding decreases with increasing damage strain and bonding will tend to $b_{\text {ult }}$ when the damage strain tends to infinity.

\section{DESTRUCTURATION IN COMPRESSION AND IN TENSION}

The yield curve of the proposed model on each sampling plane is depicted in Fig. 2. In this figure $\sigma_{\mathrm{nc}}^{\prime *}$ and $\sigma_{\mathrm{nc}}^{\prime}$ are preconsolidation pressures of the reconstituted and the structured soil, respectively. As mentioned before, the preconsolidation pressure increases with increasing amount of bonding or structure level. Therefore the ratio of these two stresses should be a function of bonding, thus:

$$
\frac{\sigma_{\mathrm{nc}}^{\prime}}{\sigma_{\mathrm{nc}}^{\prime *}}=1+b
$$

where $(1+b)$ is a decreasing function of damage strain, $\varepsilon_{\mathrm{di}}$ with its ultimate value (at a damage strain of infinity) equal to one (for metastable structure) or greater than one (for stable structure). $b$ is the amount of bonding that is defined by Eq. (20). By substituting Eq. (20) into Eq. (21), the preconsolidation pressure of the natural clay is obtained as:

$$
\sigma_{\mathrm{nc}}^{\prime}=\sigma_{\mathrm{nc}}^{\prime *} \cdot\left\{1+b_{\mathrm{ult}}+\left(b_{\mathrm{i}}-b_{\mathrm{ult}}\right) \exp \left(-h_{\mathrm{v}} \varepsilon_{\mathrm{di}}\right)\right\}
$$

By substituting the volumetric hardening rule of the model (Eq. (12)) into Eq. (22), we get:

$$
\sigma_{\mathrm{nc}}^{\prime}=\left(\sigma_{\mathrm{nc}, \mathrm{i}}^{\prime *} \cdot e^{-K \varepsilon_{\mathrm{n}, \mathrm{v}}}\right) \cdot\left\{1+b_{\mathrm{ult}}+\left(b_{\mathrm{i}}-b_{\mathrm{ult}}\right) \cdot e^{-h_{\imath} \varepsilon_{\mathrm{ud}}}\right\}
$$

where $\sigma_{\mathrm{nc}, \mathrm{i}}^{\prime *}$ is the initial preconsolidation normal stress on a given plane $i$ of the reconstituted soil and the hardening parameter $K$ is given by Eq. (12).

All parameters used in the destructuration formulation, i.e., $b_{\mathrm{i}}, b_{\mathrm{ult}}$ and $h_{\mathrm{v}}$, have a physical meaning and can be derived from oedometer tests. The amount of initial bonding parameter $b_{\mathrm{i}}$ is related to the yield stress ratio, i.e., the ratio of the preconsolidation pressure on the normal consolidation line (NCL) of the natural soil to the corresponding preconsolidation pressure on the intrinsic NCL, Fig. 4. With the assumption of the same $K_{0}$ for the natural and the reconstituted soil, the relation has the form:

$$
b_{\mathrm{i}}=\frac{\sigma_{\mathrm{nc}, \mathrm{i}}^{\prime}}{\sigma_{\mathrm{nc}, \mathrm{i}}^{\prime *}}-1=\frac{\sigma_{\mathrm{vy}}^{\prime}}{\sigma_{\mathrm{vy}}^{\prime *}}-1
$$

where $\sigma_{\mathrm{vy}}^{\prime}$ and $\sigma_{\mathrm{vy}}^{\prime *}$ are the gross yield pressure of the natural soil and the corresponding preconsolidation pressure of the reconstituted soil taken from conventional oedometer tests, respectively. The parameter $h_{\mathrm{v}}$ is a nondimensional parameter to control the rate of degradation. The value of $h_{\mathrm{v}}$ can be obtained by fitting the experimental normal consolidation line (NCL). As the value of $h_{\mathrm{v}}$ increases, the normal consolidation line of natural soil more quickly approaches the normal consolidation line of the reconstituted soil (Fig. 4). In a similar way as used to obtain $b_{\mathrm{i}}$, the parameter $b_{\text {ult }}$ can also be derived. Because, it follows from Eq. (22) that for a large damage strain $\varepsilon_{\mathrm{di}}$, the ratio between the preconsolidation normal stresses of natural soil and reconstituted soil is related to $b_{\text {ult }}$, and is $1+b_{\text {ult }}$.

In the same manner as destructuration in compression, a decrease of tensile strength can be modelled during degradation of structure. In order to do that, with the assumption of a metastable structure for destructuration in tension, the following relationship is proposed, in which the initial tensile strength $\sigma_{t, \max }^{\prime}$ (maximum tensile 

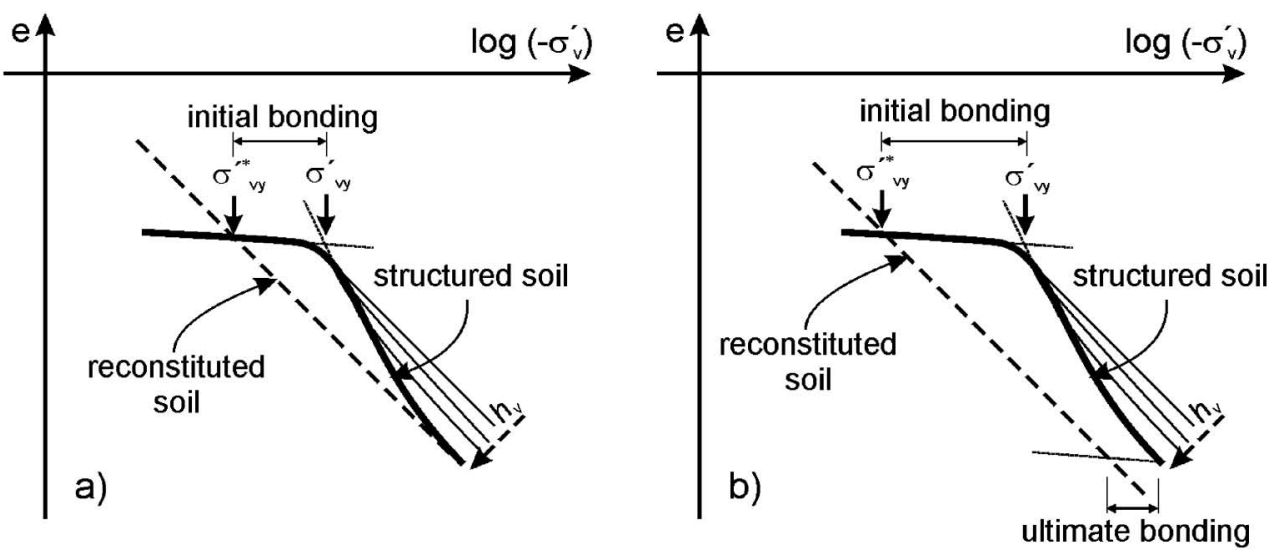

Fig. 4. Schematic description of destructuration in oedometer test: (a) Metastable structure and (b) Stable structure

strength) is related to the tensile strength of natural soil $\sigma_{\mathrm{t}}^{\prime}$ at the damage strain $\varepsilon_{\mathrm{di}}$ (Fig. 2).

$$
\frac{\sigma_{\mathrm{t}}^{\prime}}{\sigma_{\mathrm{t}, \max }^{\prime}}=\exp \left(-h_{\mathrm{v}} \varepsilon_{\mathrm{di}}\right)
$$

The above expression indicates that the tensile strength must tend to zero as the damage strain increases.

\section{MODELLING OF INHERENT ANISOTROPY}

In microstructure models the strength of soil at any direction is modelled by a so-called microstructure tensor (Pietruszczak and Mroz, 2000, 2001). In this kind of constitutive models the effect of strength anisotropy is considered by adopting a scalar anisotropy parameter defined in terms of a microstructure tensor. This concept is employed in this study to introduce strength anisotropy to the model by varying the model parameters over the sampling planes. Pietruszczak and Pande (2001) used a similar approach to implement strength anisotropy into the multilaminate framework. Cudny and Vermeer (2004) modelled a direction dependent overconsolidation ratio in the same way. As the multilaminate models are able to take into account induced anisotropy intrinsically, by introducing the inherent anisotropy the model is capable of covering a wide range of anisotropic material behaviour for stress levels below and at failure.

\section{SPATIAL DISTRIBUTION OF STRENGTH PARAMETERS IN TERMS OF MICROSTRUCTURE TENSOR}

The microstructure tensor $\mathbf{A}$ can be considered as a measure of material fabric. It can describe the spatial distribution of material parameters, for example spatial distribution of voids or cracks or arrangement of intergranular contacts. In practice, obtaining any information about $\mathbf{A}$ is very difficult, but as it will be shown, this tensor is not used directly in the calculation. The principal directions of $\mathbf{A}$, co-axial to the axis of orthotropy of the material, are denoted as $\mathbf{e}^{(1)}, \mathbf{e}^{(2)}, \mathbf{e}^{(3)}$ and $a_{1}, a_{2}, a_{3}$ are the principal values of $\mathbf{A}$. With the assumption that $\mathbf{A}$ is a symmetric tensor its spectral representation has the following form:

$$
A_{\mathrm{ij}}=a_{1} e_{\mathrm{i}}^{(1)} e_{\mathrm{j}}^{(1)}+a_{2} e_{\mathrm{i}}^{(2)} e_{\mathrm{j}}^{(2)}+a_{3} e_{\mathrm{i}}^{(3)} e_{\mathrm{j}}^{(3)}
$$

The effect of the tensor $\mathbf{A}$ at the direction of loading or any arbitrary direction can be calculated by considering a vector $\mathbf{u}$ as the unit vector of determining any arbitrary direction in the orthonormal coordinate system of $\mathbf{e}^{(1)}, \mathbf{e}^{(2)}$ and $\mathbf{e}^{(3)}$. The projection of the microstructure tensor $\mathbf{A}$ in the direction of $\mathbf{u}$ can be expressed as follows:

$$
\alpha_{\mathrm{u}}=\mathbf{A} \mathbf{u} \cdot \mathbf{u}=A_{\mathrm{ij}} u_{\mathrm{i}} u_{\mathrm{j}}
$$

The scalar parameter $\alpha_{\mathrm{u}}$ can be considered as the strength or any other property of the material at direction $\mathbf{u}$. The normalized deviatoric part $\Omega$ of the micro-structure tensor is defined as:

$$
\Omega_{\mathrm{ij}}=\left(A_{\mathrm{ij}}-\frac{1}{3} \delta_{\mathrm{ij}} A_{\mathrm{kk}}\right) /\left(\frac{1}{3} A_{\mathrm{kk}}\right)
$$

$\delta_{\mathrm{ij}}$ is known as the Kronecker's tensor, such that $\delta_{\mathrm{ij}}=1$ if $i$ $=j$ and $\delta_{\mathrm{ij}}=0$ if $i \neq j . \Omega$ is a symmetric and traceless tensor $\left(\Omega_{\mathrm{ii}}=0\right)$. In the case of cross anisotropy or transverse isotropy, having the same property for all horizontal directions and different property in the vertical direction, there are two distinct eigenvalues of $\Omega$. In the geometrical frame of principal axes of cross anisotropy $\Omega$ has the following components $\left(\mathbf{e}^{(2)}\right.$ is the unit vector at vertical direction):

$$
\boldsymbol{\Omega}=\left[\begin{array}{ccc}
-\Omega_{\mathrm{v}} / 2 & 0 & 0 \\
0 & \Omega_{\mathrm{v}} & 0 \\
0 & 0 & -\Omega_{\mathrm{v}} / 2
\end{array}\right]
$$

By substituting Eq. (28) in Eq. (27) and consideration of cross anisotropy, and defining the anisotropy ratio $A_{\mathrm{r}}$ as a ratio of vertical strength to the horizontal one, we obtain:

$$
\begin{aligned}
& \alpha_{\mathrm{u}}=\alpha_{0}\left[1-\frac{A_{\mathrm{r}}-1}{A_{\mathrm{r}}+2}\left(1-3\left(u_{\mathrm{v}}\right)^{2}\right)\right] \\
& A_{\mathrm{r}}=\frac{\alpha_{\mathrm{v}}}{\alpha_{\mathrm{h}}}=\frac{1+\Omega_{\mathrm{v}}}{1-\frac{\Omega_{\mathrm{v}}}{2}} \text { and } \alpha_{0}=\frac{A_{\mathrm{ii}}}{3}
\end{aligned}
$$




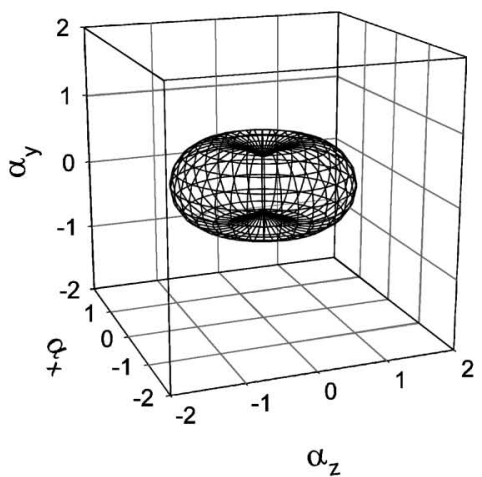

$A_{r}=0.3$

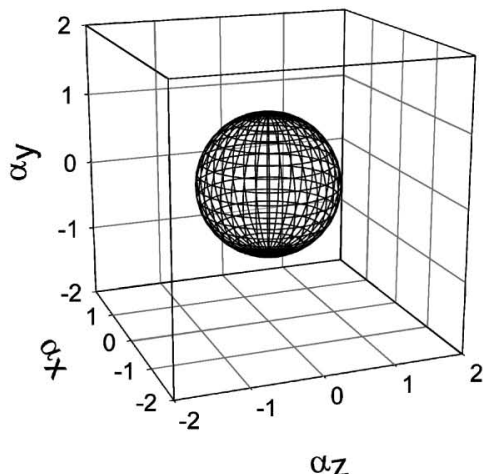

$A_{r}=1.0$

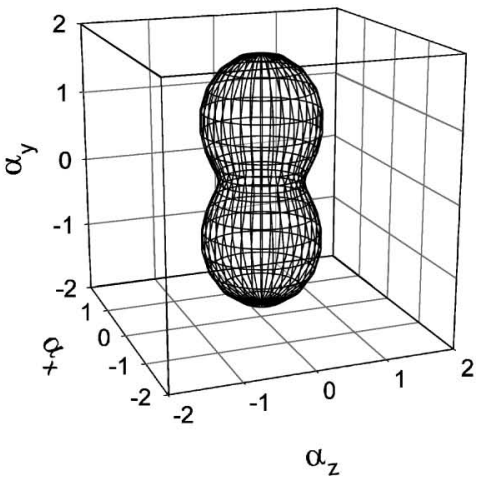

$A_{r}=3.0$

Fig. 5. Three-dimensional polar plots of spatial distribution resulting from Eq. (30) for different values of parameter $A_{\mathrm{r}}$ and $\alpha_{0}=1.0$

$u_{\mathrm{v}}$ is the vertical component of the unit vector of the direction in which the value of $\alpha_{u}$ is calculated. The three dimensional distribution of Eq. (30) is presented in Fig. 5 for different values of $A_{\mathrm{r}}$, namely $A_{\mathrm{r}}<1, A_{\mathrm{r}}=1$ and $A_{\mathrm{r}}$ $>1 . A_{\mathrm{r}}=1$ represents an isotropic soil with the same strength at any direction and $A_{\mathrm{r}}>1$ or $A_{\mathrm{r}}<1$ means increased strength at the vertical or horizontal directions respectively. $\alpha_{0}$ is the mean value of parameter $\alpha$.

As the inherent anisotropy is a consequence of anisotropic fabric which affects peak strength rather than critical state, the ultimate strength parameters $c_{\text {peak }}^{\prime}$ and $\varphi_{\text {peak }}^{\prime}$ must be determined as orientation dependent parameters according to Eq. (30). Thus, these two parameters on each sampling plane can be determined by Eqs. (32) and (33).

$$
\begin{aligned}
& c_{\text {peak }}^{\prime}=c_{0}^{\prime} \cdot\left[1-\frac{A_{\mathrm{r}}-1}{A_{\mathrm{r}}+2}\left(1-3\left(t_{\mathrm{v}}\right)^{2}\right)\right] \\
& \varphi_{\text {peak }}^{\prime}=\tan ^{-1}\left(\tan \varphi_{0}^{\prime} \cdot\left[1-\frac{A_{\mathrm{r}}-1}{A_{\mathrm{r}}+2}\left(1-3\left(t_{\mathrm{v}}\right)^{2}\right)\right]\right)
\end{aligned}
$$

$t_{\mathrm{v}}$ is the vertical component of the unit vector $\mathbf{t}$ in the direction of the shear stress vector on the respective sampling plane. $c_{0}^{\prime}$ and $\varphi_{0}^{\prime}$ are the mean effective cohesion and the mean effective friction angle, respectively and determined by Eq. (34). The parameter of anisotropy ratio $A_{\mathrm{r}}$ is defined by ratio of the vertical strength to the horizontal one, Eq. (35).

$$
\begin{aligned}
& c_{0}^{\prime}=\frac{c_{\text {peak }, \mathrm{v}}^{\prime}+2 c_{\text {peak }, \mathrm{h}}^{\prime}}{3} \text { and } \\
& \tan \varphi_{0}^{\prime}=\frac{\tan \varphi_{\text {peak }, \mathrm{v}}^{\prime}+2 \tan \varphi_{\text {peak }, \mathrm{h}}^{\prime}}{3} \\
& A_{\mathrm{r}}=\frac{c_{\text {peak }, \mathrm{v}}^{\prime}}{c_{\text {peak }, \mathrm{h}}^{\prime}}=\frac{\tan \varphi_{\text {peak }, \mathrm{v}}^{\prime}}{\tan \varphi_{\text {peak }, \mathrm{h}}}
\end{aligned}
$$

\section{EFFECT OF INHERENT ANISOTROPY ON FAILURE CRITERION}

In this section the influence of strength anisotropy on the behaviour of soil on the level of a stress point is dis-

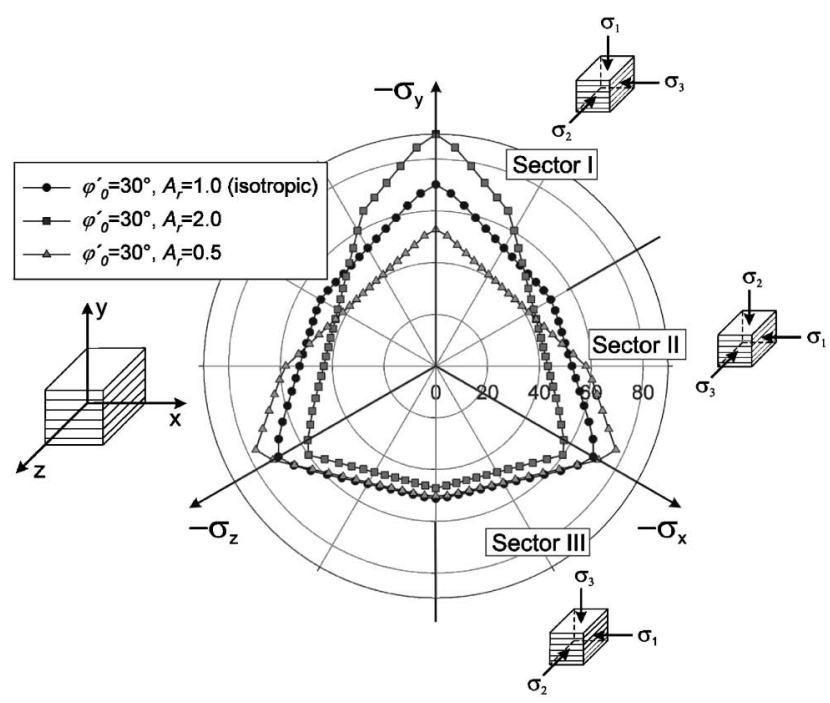

Fig. 6. Failure surface in deviatoric plane for different values of $A_{\mathrm{r}}$

cussed. The trace of the failure surface in the deviatoric plane is depicted in Fig. 6 for three values of $A_{\mathrm{r}}$, namely $A_{\mathrm{r}}=0.5,1.0$ (isotropic behaviour) and 2.0. The mean friction angle $\varphi_{0}^{\prime}$ is assumed to be $30^{\circ}$, therefore for $A_{\mathrm{r}}=$ $2.0, \varphi_{\mathrm{v}}^{\prime}=40.89^{\circ}, \varphi_{\mathrm{h}}^{\prime}=23.41^{\circ}$ and for $A_{\mathrm{r}}=0.5, \varphi_{\mathrm{v}}^{\prime}=19.1^{\circ}$, $\varphi_{\mathrm{h}}^{\prime}=34.71^{\circ}$. To investigate the influence of the intermediate stress $\sigma_{2}$ on the failure criterion of this model, the failure surface in the deviatoric plane is separated into three sectors, as shown in Fig. 6. Figure 7 presents the variation of the calculated ultimate effective friction angle with parameter $R_{\mathrm{b}}=\left(\sigma_{2}-\sigma_{3}\right) /\left(\sigma_{1}-\sigma_{3}\right)$, which expresses the relative magnitude of $\sigma_{2}$, in different sectors for the two anisotropic cases, namely $A_{\mathrm{r}}=0.5$ and $A_{\mathrm{r}}=$ 2.0. It can be seen that depending on the value of the anisotropy ratio $A_{\mathrm{r}}$ the maximum and the minimum friction angles are obtained in sector I or II.

In the proposed model the orientation of principal stress axes with respect to the material axes has a significant influence on the failure criterion. The curves of Fig. 8 are obtained from the orientation of principal direction of stress about $\mathbf{z}$ for $0,60^{\circ}$ and $90^{\circ}$. It follows 

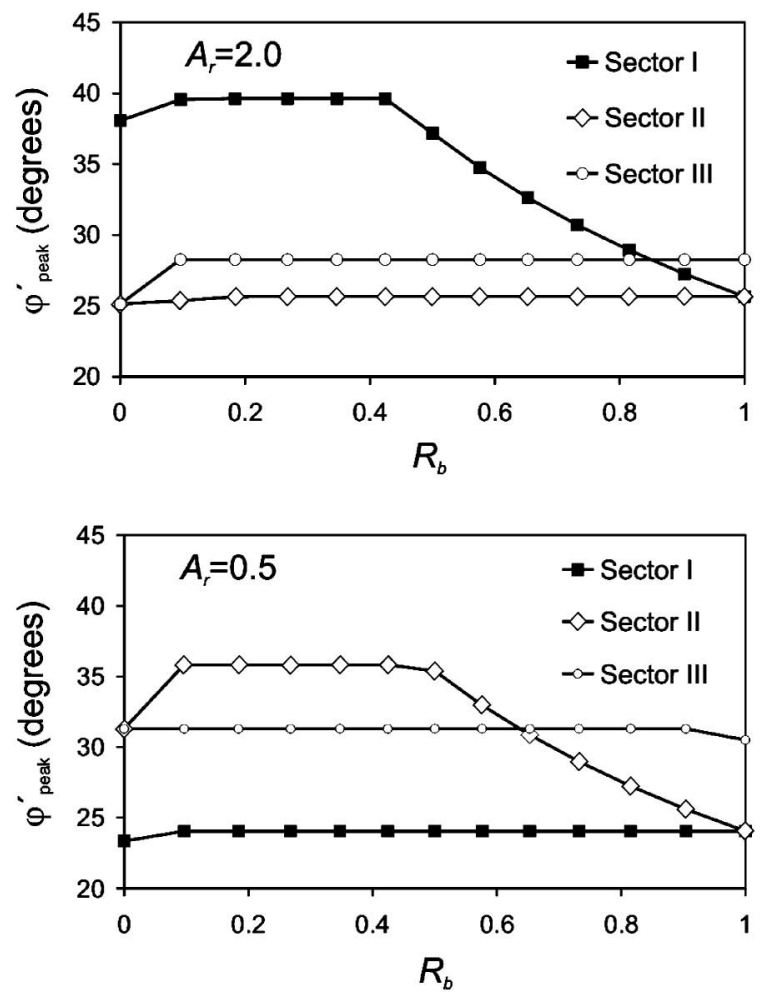

Fig. 7. Calculated ultimate friction angle $\varphi_{\text {peak }}^{\prime}$ versus parameter $\boldsymbol{R}_{\mathrm{b}}$ $\left(\varphi_{0}^{\prime}=30^{\circ}\right)$

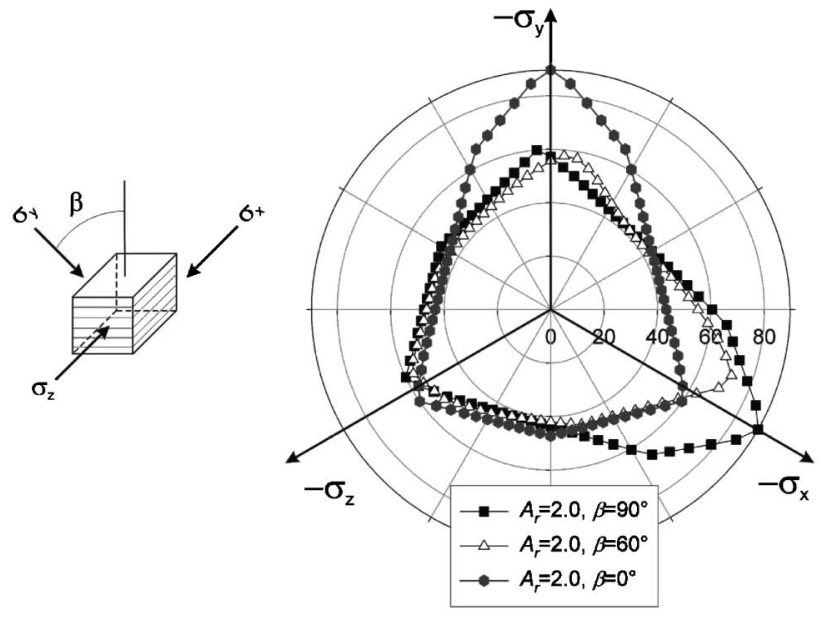

Fig. 8. Failure surface in deviatoric plane for different principal stress axes orientation

from these graphs that quite complex failure behaviour can be modelled by this model without mathematical complexity.

\section{EFFECT OF ANISOTROPY ON DESTRUCTURATION}

In the previous section, the parameter $b_{\mathrm{i}}$ has been introduced, which is the amount of initial bonding on a sampling plane. Due to the mathematical formulation of the multilaminate framework its value is independent of other planes. As the structure of soils causes a variation of the yield surface (Leroueil and Vaughan, 1990) in different directions, it is reasonable to assume that in anisotropic soils, the amount of bonding is different in various directions. Therefore the parameter $b_{\mathrm{i}}$ should be a direction dependent parameter and the spatial distribution of $b_{\mathrm{i}}$ can be defined by means of Eq. (30). Thus:

$$
b_{\mathrm{i}}=b_{0}\left[1-\frac{A_{\mathrm{r}}-1}{A_{\mathrm{r}}+2}\left(1-3\left(n_{\mathrm{v}}\right)^{2}\right)\right]
$$

where $b_{0}$ and $A_{\mathrm{r}}$ are the mean value of the amount of initial bonding (Eq. (37)) and the anisotropy ratio, respectively and $n_{\mathrm{v}}$ is the vertical component of the unit vector normal to the representative sampling plane.

$$
b_{0}=\frac{b_{\mathrm{i}, \mathrm{v}}+2 b_{\mathrm{i}, \mathrm{h}}}{3}
$$

$b_{\mathrm{i}, \mathrm{v}}$ and $b_{\mathrm{i}, \mathrm{h}}$ are the amount of initial bonding in vertical and horizontal directions. Here the value of $A_{\mathrm{r}}$ can be obtained from the vertical and horizontal gross yield pressures of natural soil:

$$
A_{\mathrm{r}}=\frac{b_{\mathrm{i}, \mathrm{v}}}{b_{\mathrm{i}, \mathrm{h}}}=\frac{\sigma_{\mathrm{nc}, \mathrm{i}, \mathrm{v}}^{\prime}-\sigma_{\mathrm{nc}, \mathrm{i}}^{\prime *}}{\sigma_{\mathrm{nc}, \mathrm{i}, \mathrm{h}}^{\prime}-\sigma_{\mathrm{nc}, \mathrm{i}}^{\prime *}}
$$

$\sigma_{\mathrm{nc}, \mathrm{i}, \mathrm{v}}^{\prime}$ is the gross yield pressure of natural soil if the pressure is applied in the direction normal to the bedding plane of the soil and in the same manner $\sigma_{\mathrm{nc}, \mathrm{i}, \mathrm{h}}^{\prime}$ is the gross yield pressure of natural soil if the pressure is applied in the direction parallel to the bedding plane of soil. It follows from Eq. (38) that the difference between $\sigma_{\mathrm{nc}, \mathrm{i}, \mathrm{v}}^{\prime}$ and $\sigma_{\text {nc,i,h }}^{\prime}$ increases with increasing $A_{\mathrm{r}}$ and $b_{0}$.

If results of oedometer tests are available for both vertically and horizontally trimmed samples, the value of the anisotropy ratio $A_{\mathrm{r}}$ can be easily obtained from Eq. (38). Since the main reason for having inherent anisotropic behaviour (in strength or preconsolidation pressure) is anisotropy in bonding, it is assumed here that the values of $A_{\mathrm{r}}$ obtained from Eqs. (38) and (35) are the same, but this is not necessarily required from the model.

As the bonding parameter is used in the definition of the preconsolidation normal stress and tensile stress it follows that by defining the bonding parameter as a direction dependent parameter, the above mentioned parameters are also direction dependent, which is the most important feature of the model.

\section{NUMERICAL SIMULATION OF ELEMENT TESTS}

In this section the proposed model is applied to numerical simulation of element tests on some stiff clays. To verify the proposed model, some numerical triaxial tests in undrained conditions and some oedometer tests on two different stiff clays have been carried out. The aforementioned natural clays are Pietrafitta clay (Burland et al., 1996) and Pappadai clay (Cotecchia and Chandler, 1997). Although there is no information about the anisotropic behaviour of Pietrafitta clay available, some numerical tests have been performed by assuming inherent anisotropy in bonding to show the effect of anisotropy on 
the mechanical behaviour of natural clays.

\section{PIETRAFITTA CLAY}

Burland et al. (1996) presented experimental data on the mechanical behaviour of four stiff cohesive clays of Plio-Pleistocene age, Todi clay, Pietrafitta clay, Vallericca clay and Corinth marl. Todi clay and Pietrafitta clay are lacustrine, while Vallericca clay and Corinth marl were deposited in marine environments. Here the stiff natural Pietrafitta clay is chosen to validate the proposed model for numerical simulation of compressibility and undrained behaviour. Pietrafitta clay samples were taken from about $30 \mathrm{~km}$ south-west of Perugia in central Italy. As geological studies show, the maximum overburden thickness experienced by Pietrafitta clay is estimated to be about $150 \mathrm{~m}$.

\section{MATERIAL PROPERTIES}

The triaxial tests of the natural clays have been carried out on specimens $38 \mathrm{~mm}$ in diameter, $76 \mathrm{~mm}$ in height, cut from high-quality block samples. The tests have been performed at the initial effective stresses. Burland et al. (1996) presented experimental data (drained and undrained shear strength and compressibility) in reconstituted and natural states. Therefore the experimental data of strength parameters and compressibility of soil in intact state and reconstituted state can be obtained from their work and is given in Table 1. The intrinsic failure line is

Table 1. Experimental data of Pietrafitta clay (Burland et al., 1996)

\begin{tabular}{l|c|c|c}
\hline \multicolumn{1}{c|}{ Description } & Symbol & Unit & Value \\
\hline intrinsic compression index & $C_{\mathrm{c}}^{*}$ & {$[-]$} & 0.523 \\
\hline intrinsic swelling index & $C_{\mathrm{s}}^{*}$ & {$[-]$} & 0.118 \\
\hline initial void ratio & $e_{0}$ & {$[-]$} & 1.14 \\
\hline intrinsic peak cohesion & $c_{\text {peak }}^{*}$ & {$[\mathrm{kPa}]$} & 0 \\
\hline intrinsic peak friction angle & $\varphi_{\text {peak }}^{\prime *}$ & {$\left[{ }^{\circ}\right]$} & $28.4-33.0$ \\
\hline intrinsic vertical yield stress & $\sigma_{\mathrm{vy}}^{\prime *}$ & {$[\mathrm{kPa}]$} & -490 \\
\hline intact vertical yield stress & ${\sigma_{\mathrm{vy}}^{\prime *}}^{*}$ & {$[\mathrm{kPa}]$} & -1050 \\
\hline
\end{tabular}

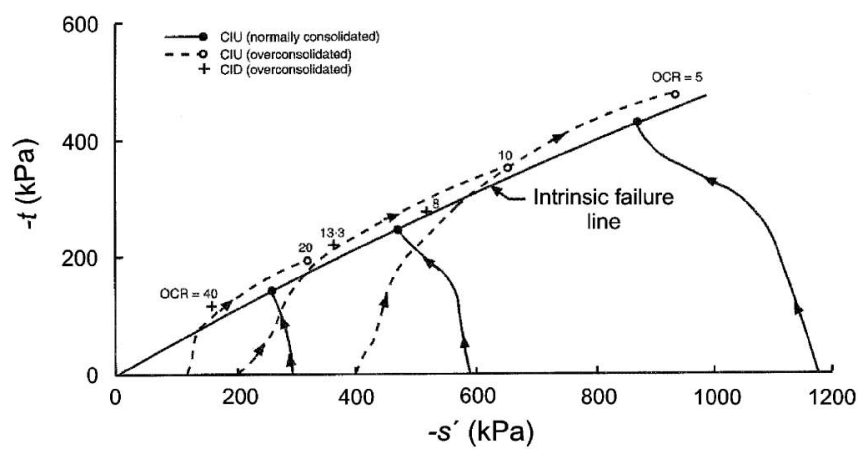

Fig. 9. Peak strength and undrained stress paths of triaxial test of reconstituted Pietrafitta clay (Burland et al., 1996) depicted in $s^{\prime}-t$ space in Fig. 9 for normally consolidated material determined from three undrained tests. $s^{\prime}=\left(\sigma_{1}^{\prime}\right.$ $\left.+\sigma_{3}^{\prime}\right) / 2$ and $t=\left(\sigma_{1}-\sigma_{3}\right) / 2$ are stress invariants. As seen, the failure line is slightly curved with $\varphi_{\text {peak }}^{\prime *}=$ $33.0^{\circ}$ at $s^{\prime}=-300 \mathrm{kPa}$ and the secant value of $\varphi_{\text {peak }}^{\prime *}=$ $28.4^{\circ}$ at $s^{\prime}=-1000 \mathrm{kPa}$.

The model parameters are calculated from Table 1 and are given in Table 2. Some of the parameters can be directly obtained but some have to be estimated such as $v^{\prime}$, $A_{\text {mat }}, \psi, \varphi_{\mathrm{m}}^{\prime *}, \psi_{\mathrm{m}, \mathrm{min}}$ and $A_{\mathrm{d}}$. The mean value of initial bonding $b_{0}$ is calculated from the yield stress ratio (ratio of the intact vertical yield stress $\sigma_{\mathrm{vy}}^{\prime}$ to the intrinsic vertical yield stress $\sigma_{\mathrm{vy}}^{\prime *}$ ) by means of Eqs. (24) and (37). As it is aimed to model the mechanical behaviour of Pietrafitta for the mean effective stress around $-1000 \mathrm{kPa}$, the peak effective friction angle of $28.4^{\circ}$ has been chosen for all numerical simulations presented in this section. To determine the value of $h_{\mathrm{v}}$ some numerical oedometer tests have been carried out to fit the experimental results.

The compressibility and undrained shear behaviour of this clay is simulated in isotropic $\left(A_{\mathrm{r}}=1\right)$ and anisotropic ( $A_{\mathrm{r}}=0.5$ and $A_{\mathrm{r}}=2$ ) cases by the proposed model. It is assumed here that only plastic volumetric strains contribute to destructuration $\left(A_{\mathrm{d}}=0\right)$.

Table 2. Equivalent input data for the multilaminate model for Pietrafitta clay

\begin{tabular}{|c|c|c|c|}
\hline Description & Symbol & Unit & Value \\
\hline intrinsic compression index & $\lambda^{*}$ & {$[-]$} & 0.2270 \\
\hline intrinsic swelling index & $\kappa^{*}$ & {$[-]$} & 0.0512 \\
\hline Poisson's ratio & $v^{\prime}$ & {$[-]$} & 0.20 \\
\hline deviatoric hardening parameter & $A_{\text {mat }}$ & {$[-]$} & 0.025 \\
\hline $\begin{array}{l}\text { shape parameter of volumetric } \\
\text { part }\end{array}$ & $M_{\mathrm{a}}$ & {$[-]$} & $0.67 \tan \varphi_{\text {peak }}^{\prime}$ \\
\hline initial void ratio & $e_{0}$ & {$[-]$} & 1.14 \\
\hline mean cohesion & $c_{0}^{\prime}$ & {$[\mathrm{kPa}]$} & 0 \\
\hline mean friction angle & $\varphi_{0}^{\prime}$ & {$\left[{ }^{\circ}\right]$} & 28.4 \\
\hline dilation angle & $\psi$ & {$\left[{ }^{\circ}\right]$} & 0 \\
\hline $\begin{array}{l}\text { mobilised friction angle at } \\
\text { minimum mobilised dilatancy }\end{array}$ & $\varphi_{\mathrm{m}}^{\prime *}$ & {$\left[{ }^{\circ}\right]$} & 9 \\
\hline $\begin{array}{l}\text { minimum of mobilised dilatancy } \\
\text { angle }\end{array}$ & $\psi_{\mathrm{m}, \min }$ & {$\left[{ }^{\circ}\right]$} & -17 \\
\hline failure ratio & $R_{\mathrm{f}}$ & {$[-]$} & 0.9 \\
\hline mean initial bonding & $b_{0}$ & {$[-]$} & 1.14 \\
\hline rate of damage & $h_{\mathrm{v}}$ & {$[-]$} & 10.0 \\
\hline $\begin{array}{l}\text { initial preconsolidation normal } \\
\text { stress }\end{array}$ & $\sigma_{\mathrm{nc}, \mathrm{i}}^{\prime *}$ & {$[\mathrm{kPa}]$} & -490 \\
\hline $\begin{array}{l}\text { parameter of proportion of plastic } \\
\text { strains }\end{array}$ & $A_{\mathrm{d}}$ & {$[-]$} & 0 \\
\hline tensile strength & $\sigma_{\mathrm{t}}^{\prime}$ & {$[\mathrm{kPa}]$} & 0 \\
\hline
\end{tabular}




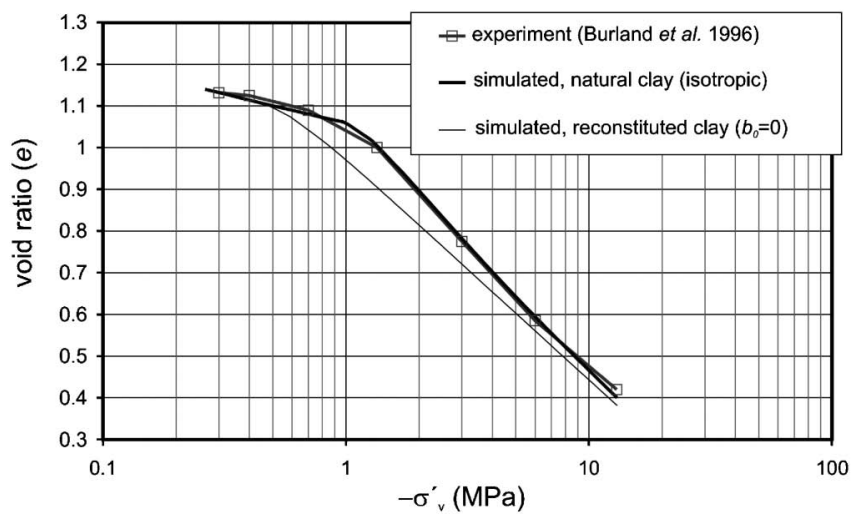

Fig. 10. Comparison of simulation and experimental normal compression lines of oedometer test for Pietrafitta clay

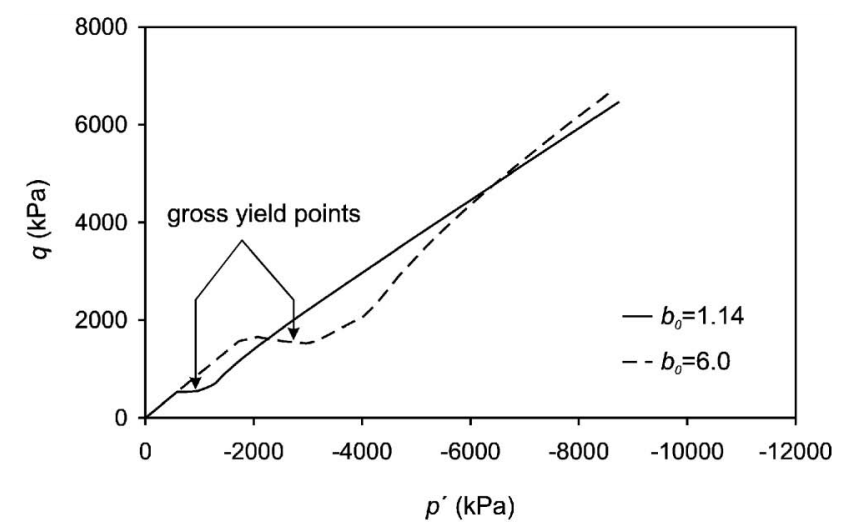

Fig. 11. Influence of $b_{0}$ on $K_{0}$ stress path

\section{RESULTS}

\section{Compressibility Behaviour}

Comparison between the experimental normal compression curve and the simulated curves is shown in Fig. 10. It is seen that the model has the capability of modelling of the compressibility of the soil with good accuracy. The calculated gross yield is roughly $-1050 \mathrm{kPa}$, as expected.

The parameter of mean initial bonding $b_{0}$ determines the intact gross yield stress. The influence of this parameter on the simulated $K_{0}$ stress path is shown in Fig. 11. It should be noted that the value of 6.0 for $b_{0}$ is only assumed to show the influence of this parameter.

\section{Effect of Initial Anisotropy}

The influence of the anisotropy ratio $A_{\mathrm{r}}$ (inherent anisotropy of strength, bonding and preconsolidation pressure) on the normal compression line obtained from an oedometer test on a vertically trimmed sample is shown in Fig. 12 and it can be seen that the differences are not significant. However, the anisotropy ratio $A_{\mathrm{r}}$ has a more pronounced influence on the normal consolidation lines for samples tested at different orientations. Effect of sample orientation is depicted in Fig. 13 for two different values of mean initial bonding, namely $b_{0}=1.14$ and $b_{0}=$

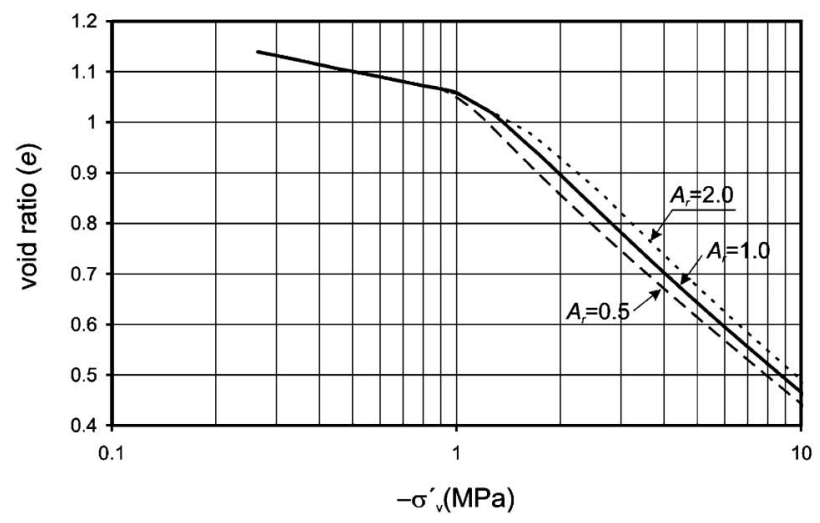

Fig. 12. Effect of anisotropy ratio $A_{\mathrm{r}}$ on normal compression line

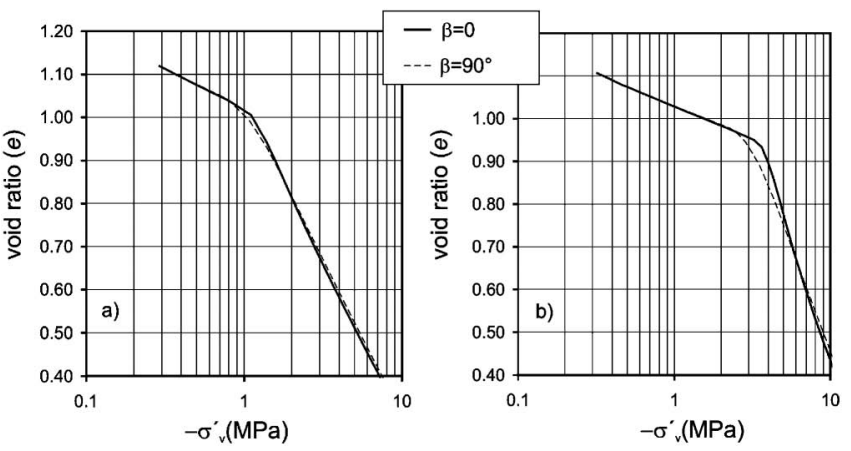

Fig. 13. Effect of sample direction on the compressibility: (a) $b_{0}=$ 1.14, $A_{\mathrm{r}}=2.0$ and (b) $b_{0}=6.0, A_{\mathrm{r}}=2.0$
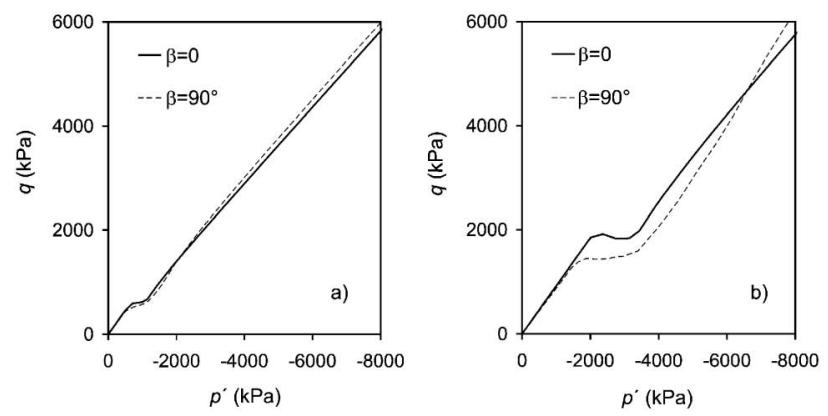

Fig. 14. Effect of sample direction on $K_{0}$ stress path: (a) $b_{0}=1.14, A_{\mathrm{r}}$ $=2.0$ and (b) $b_{0}=6.0, A_{\mathrm{r}}=2.0$

6.0. For both simulations the value of anisotropy ratio $A_{\mathrm{r}}$ is the same and equal to 2.0. The corresponding $K_{0}$ stress paths are plotted in Fig. 14. As seen, the rotation of sample changes the gross yield stresses from $\sigma_{\mathrm{vy}}^{\prime} \approx-3200 \mathrm{kPa}$ at $\beta=0^{\circ}$ to $\sigma_{\mathrm{vy}}^{\prime} \approx-2300 \mathrm{kPa}$ at $\beta=90^{\circ}$ for the sample with $b_{0}=6.0$ and from $\sigma_{\mathrm{vy}}^{\prime} \approx-1100 \mathrm{kPa}$ at $\beta=0^{\circ}$ to $\sigma_{\mathrm{vy}}^{\prime} \approx$ $-750 \mathrm{kPa}$ at $\beta=90^{\circ}$ for the sample with $b_{0}=1.14$ (Fig. 13). A similar pattern has been observed in the laboratory for anisotropic natural soils, e.g., Lojander and Vepsäläinen (2001). It follows from Fig. 14 that the value of the coefficient of earth pressure at rest $K_{0}$ changes with the orientation of the principal stress directions. The changes in gross yield stress and $K_{0}$ increase with increas- 


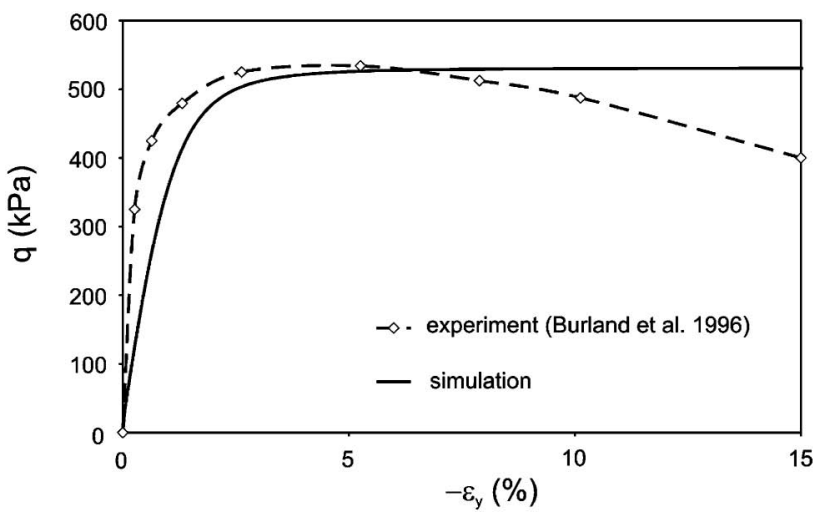

Fig. 15. Comparison of simulation and experimental deviatoric stressaxial strain curves for undrained triaxial compression test for Pietrafitta clay

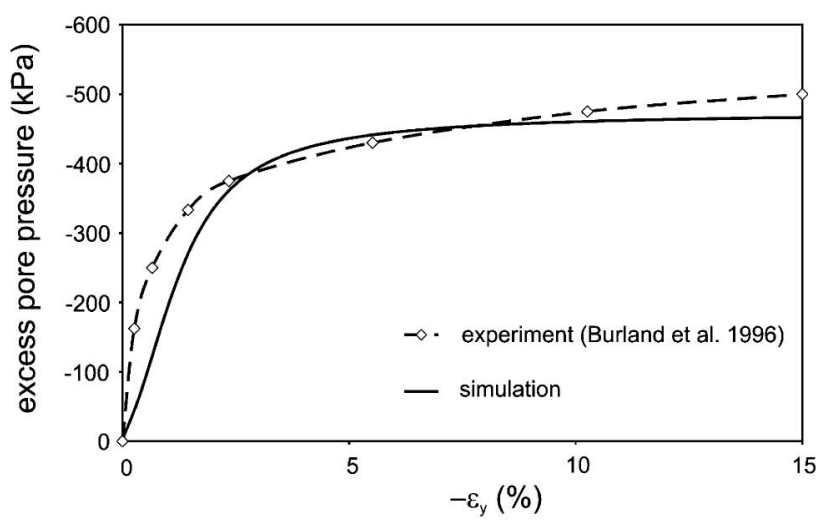

Fig. 16. Comparison of simulation and experimental excess pore pressure-axial strain curves of undrained triaxial compression test for Pietrafitta clay

ing $b_{0}$, therefore for heavily structured soil, the effect of the rotation of sample orientation has a significant effect on the mechanical behaviour of anisotropic natural soil.

\section{Undrained Behaviour}

Figures 15 and 16 show the simulated and experimental stress-strain curves of natural Pietrafitta clay consolidated to the value of $-760 \mathrm{kPa}$ assuming $A_{\mathrm{r}}=1$, i.e., isotropic bonding. Burland et al. (1996) shows stressstrain curves of this clay for various values of confining pressure. But here the aforementioned confining pressure is chosen, representing a slight overconsolidation $\left(\sigma_{\mathrm{nc}}^{\prime}=\right.$ $-1050 \mathrm{kPa}$ ). As seen from Figs. 15 and 16 the model has the capability of simulating the undrained behaviour of Pietrafitta clay, at least up to about 5\% vertical strain. It follows from the experimental stress-strain curves of Pietrafitta clay that this soil exhibits a stiffer behaviour in the beginning of the test as compared to the numerical simulation which could be an effect of small strain stiffness which is not taken into account in this version of the model.

The corresponding experimental effective stress paths and results of simulations of undrained triaxial compression and extension tests are shown in Fig. 17. It follows

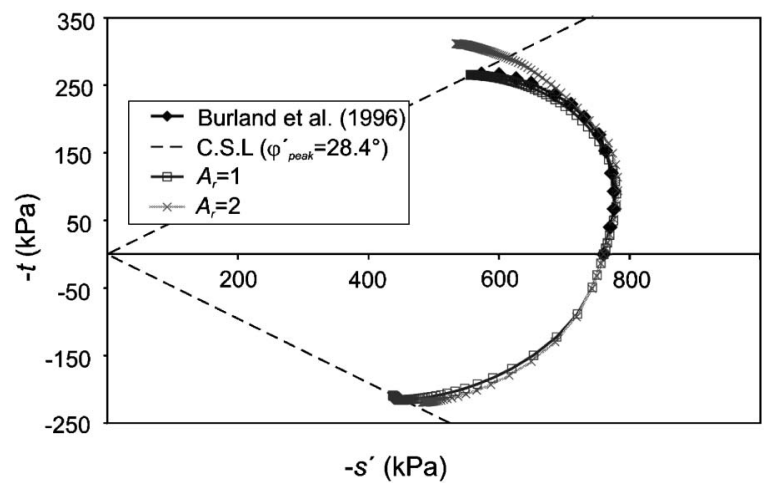

Fig. 17. Undrained stress paths of simulated and experimental triaxial tests for Pietrafitta clay in isotropic and anisotropic conditions

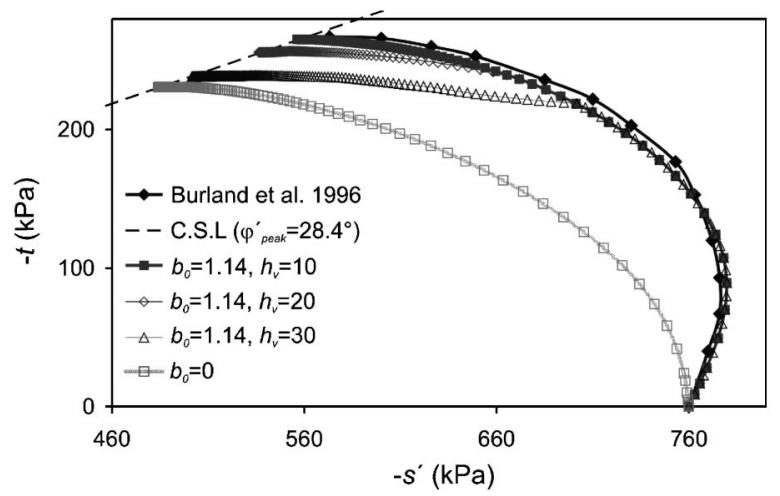

Fig. 18. Effect of structure on the simulated undrained stress paths of triaxial compression test for Pietrafitta clay

that stress paths are predicted well but anisotropic bonding has a minor effect. However, it can be seen that the stress path for $A_{\mathrm{r}}=2$ terminates above the critical state line which is a consequence of the anisotropic strength considered in this simulation.

Figure 18 shows the effect of structure on the obtained undrained stress paths. By increasing the rate of destructuration $\left(h_{\mathrm{v}}\right)$, the simulated undrained stress paths approach the stress path of the reconstituted one $\left(b_{0}=0\right)$ in the later stages of the stress path. Isotropic bonding is considered in this particular case.

\section{PAPPADAI CLAY}

As a second example, natural Pappadai clay has been chosen. Results of the experimental work on natural Pappadai clay are compared with the model simulations.

Pappadai clay is a stiff natural clay which was deposited in a quiet sea about 1.3 million years ago, during the Pleistocene age. The soil samples were obtained from a block sample at a depth of $25.4 \mathrm{~m}$ from the Montemesola Basin, near Taranto, Italy. There was subsequent erosion of some $120 \mathrm{~m}$ at the sampling location, resulting in the clay being overconsolidated. The mechanical behaviour of reconstituted and natural Pappadai clay has been studied by Cotecchia (1996) and published in Cotecchia and Chandler (1997). The experimental parameters have been 
Table 3. Experimental data of Pappadai clay (Cotecchia and Chandler, 1997)

\begin{tabular}{l|c|c|c}
\hline \multicolumn{1}{c|}{ Description } & Symbol & Unit & Value \\
\hline intrinsic compression index & $\lambda^{*}$ & {$[-]$} & 0.152 \\
\hline intact swelling index & $\kappa^{*}$ & {$[-]$} & 0.0178 \\
\hline initial void ratio & $e_{0}$ & {$[-]$} & 0.98 \\
\hline inclination of C.S.L. & $M_{\mathrm{c}}^{*}$ & {$[-]$} & 0.835 \\
\hline intrinsic vertical yield stress & $\sigma_{\mathrm{vy}}^{\prime *}$ & {$[\mathrm{kPa}]$} & -750 \\
\hline intact vertical yield stress & $\sigma_{\mathrm{vy}}^{\prime}$ & {$[\mathrm{kPa}]$} & -2600 \\
\hline
\end{tabular}

Table 4. Model parameters for Pappadai clay

\begin{tabular}{|c|c|c|c|}
\hline Description & Symbol & Unit & Value \\
\hline intrinsic compression index & $\lambda^{*}$ & {$[-]$} & 0.152 \\
\hline intrinsic swelling index & $\kappa^{*}$ & {$[-]$} & 0.0178 \\
\hline Poisson's ratio & $v^{\prime}$ & {$[-]$} & 0.20 \\
\hline deviatoric hardening parameter & $A_{\text {mat }}$ & {$[-]$} & 0.025 \\
\hline $\begin{array}{l}\text { shape parameter of volumetric } \\
\text { part }\end{array}$ & $M_{\mathrm{a}}$ & {$[-]$} & $0.75 \tan \varphi_{\text {peak }}^{\prime}$ \\
\hline initial void ratio & $e_{0}$ & {$[-]$} & 0.98 \\
\hline mean cohesion & $c_{0}^{\prime}$ & {$[\mathrm{kPa}]$} & 0 \\
\hline mean friction angle & $\varphi_{0}^{\prime}$ & {$\left[{ }^{\circ}\right]$} & 21.5 \\
\hline dilation angle & $\psi$ & {$\left[{ }^{\circ}\right]$} & 0 \\
\hline $\begin{array}{l}\text { mobilised friction angle at } \\
\text { minimum mobilised dilatancy }\end{array}$ & $\varphi_{\mathrm{m}}^{\prime *}$ & {$\left[{ }^{\circ}\right]$} & 8 \\
\hline $\begin{array}{l}\text { minimum of mobilised dilatancy } \\
\text { angle }\end{array}$ & $\psi_{\mathrm{m}, \min }$ & {$\left[{ }^{\circ}\right]$} & -8 \\
\hline failure ratio & $R_{\mathrm{f}}$ & {$[-]$} & 0.9 \\
\hline mean initial bonding & $b_{0}$ & {$[-]$} & 2.5 \\
\hline rate of damage & $h_{\mathrm{v}}$ & {$[-]$} & 13.0 \\
\hline $\begin{array}{l}\text { initial preconsolidation normal } \\
\text { stress }\end{array}$ & $\sigma_{\mathrm{nc}, \mathrm{i}}^{* *}$ & {$[\mathrm{kPa}]$} & -750 \\
\hline $\begin{array}{l}\text { parameter of proportion of plastic } \\
\text { strains }\end{array}$ & $A_{\mathrm{d}}$ & {$[-]$} & 0 \\
\hline tensile strength & $\sigma_{\mathrm{t}}^{\prime}$ & {$[\mathrm{kPa}]$} & 0 \\
\hline
\end{tabular}

taken from the experimental graphs which were provided in Cotecchia and Chandler (1997). Table 3 summarises the values of experimental compressibility and strength parameters of reconstituted and natural Pappadai clay. A set of oedometer test on both natural and reconstituted Pappadai clay were used to determine the compressibility parameters, $\lambda^{*}, \kappa^{*}, \sigma_{\mathrm{vy}}^{\prime}$ and $\sigma_{\mathrm{vy}}^{\prime *}$.

The equivalent model parameters have been calculated from Table 3 and are given in Table 4. Some parameters have to be estimated such as $v^{\prime}, A_{\mathrm{mat}}, M_{\mathrm{a}}, \varphi_{\mathrm{m}}^{\prime *}, \psi_{\mathrm{m}, \mathrm{min}}$ and $A_{\mathrm{d}}$. An isotropic structure has been assumed.

The experimental oedometer tests have been carried out with incremental loading to a maximum stress of about $-7 \mathrm{MPa}$ in a conventional oedometer test, and to a maximum stress of about $-25 \mathrm{MPa}$ in a high-pressure

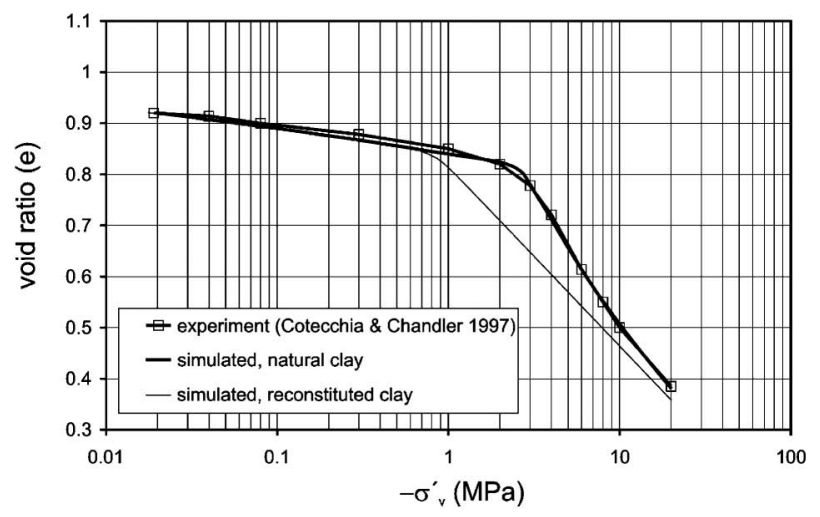

Fig. 19. Comparison of simulation and experimental normal compression lines of oedometer test for Pappadai clay

oedometer test with constant rate of strain compression, Cotecchia and Chandler (1997). The simulated compressibility behaviour under oedometer conditions for natural and reconstituted Pappadai clay is plotted in Fig. 19 together with experimental data for primary loading. It can be seen that the simulated curve matches the experimental curve (Fig. 19) quite accurately. The initial swelling curve of oedometer exhibits the very stiff behaviour of natural clay. The gross yield stress of natural clay from both experimental and numerical oedometer tests is about $-2600 \mathrm{kPa}$.

\section{SUMMARY}

A multilaminate type of constitutive model for structured soils has been presented. It has been shown that the model is able to take into account two important features of natural soils namely destructuration and anisotropy. The effects of inherent anisotropy in strength and in structure, introduced into the model by a microstructure tensor, on the mechanical behaviour of natural clays has been shown by numerical simulations of compressibility and undrained shear behaviour of two lightly overconsolidated natural soils, namely Pietrafitta and Pappadai clays. It has been assumed that the anisotropic behaviour of natural soils is due to the anisotropy in their structure and therefore the same value of anisotropy ratio has been used for anisotropy in strength and bonding. Although in the selected soils anisotropy of structure does not play a significant role, it has been demonstrated that the effect of inherent anisotropy becomes significant with increasing amount of bonding. It can be anticipated that these features will have a significant influence on the results from numerical analysis of practical boundary value problems such as deep excavations, tunnels and embankments.

\section{REFERENCES}

1) Amorosi, A. and Rampello, S. (1998): The influence of natural soil structure on the mechanical behaviour of a stiff clay, The Geotechnics of Hard Soils-Soft Rocks (eds. by Evangelista and Picarel- 
li), 395-401.

2) Baudet, B. and Ho, E. W. L. (2004): On the behaviour of deep-ocean sediments, Géotechnique, 54(9), 571-580.

3) Baudet, B. and Stallebrass, S. (2004): A constitutive model for structured clays, Géotechnique, 54(4), 269-278.

4) Bažant, Z. P. and Oh, B. H. (1985): Microplane model for progressive fracture of concrete and rock, Journal of Engineering Mechanics, ASCE, 11(4), 559-582.

5) Brinkgreve, R. B. J., Broere, W. and Waterman, D. (2006): Plaxis, Finite element code for soil and rock analyses, users manual, The Netherlands.

6) Burland, J. B. (1990): On the compressibility and shear strength of natural clays, Géotechnique, 40(3), 329-378.

7) Burland, J. B., Rampello, S., Georgiannou and Calabresi, G. (1996): A laboratory study of strength of four stiff clays, Géotechnique, 46(3), 491-514.

8) Cotecchia, F. (1996): The effects of structure on the properties of an Italian Pleistocene clay, Ph.D. Thesis, Department of Civil and Environmental Engineering, University of London, London, UK.

9) Cotecchia, F. and Chandler, R. J. (1997): The influence of structure on the pre-failure behaviour of a natural clay, Géotechnique, 47(3), 523-544.

10) Cotecchia, F. and Chandler, R. J. (2000): A general framework for the mechanical behaviour of clays, Géotechnique, 50(4), 431-447.

11) Cudny, M. and Vermeer, P. A. (2004): On the modelling of anisotropy and destructuration of soft clays within the multilaminate framework, Computers and Geotechnics, 31, 1-22.

12) Elliott, G. M. and Brown, E. T. (1985): Yield of a soft, high porosity rock, Géotechnique, 35(4), 413-423.

13) Gens, A. and Nova, R. (1993): Conceptual base for a constitutive model for bonded soils and weak rocks, Proc. International Symposium on Geotechnical Engineering of Hard Soils-Soft Rocks, Athens, 1, 485-494.

14) Kavvadas, M. and Amorosi, A. (2000): A constitutive model for structured soils, Géotechnique, 50(3), 263-273.

15) Koskinen, M., Karstunen, M. and Wheeler, S. J. (2002): Modelling destructuration and anisotropy of a natural soft clay, Proc. 5th European Conf. Numerical Methods in Geotechnical Engineering (ed. by P. Mestat), Presses de l'ENPC/LCPC, Paris, 11-20.

16) Lambe, T. W. and Whitman, R. V. (1969): Soil Mechanics, New York, Wiley.

17) Leroueil, S., Tavenas, F., Brucy, F., La Rochelle, P. and Roy, J. (1979): Behaviour of destructured natural clays, J. Soil Mech. Fdns Div. Am. Soc. Civ. Engrs, 105(GT6), 759-778.

18) Leroueil, S. and Vaughan, P. R. (1990): The general and congruent effects of structure in natural soils and weak rocks, Géotechnique, 40(3), 467-488.

19) Liu, M. D. and Carter, J. P. (2002): A structured cam clay model, Canadian Geotechnical Journal, 39(6), 1313-1332.
20) Lojander, M. and Vepsäläinen, P. (2001): Competition to calculate settlements at Haarajoki test embankment, Final Report, Finnish Road Administration, Helsinki.

21) Nova, R., Castellanza, R. and Tamagnini, C. (2003): A constitutive model for bonded geomaterials subject to mechanical and/or chemical degradation, Int. J. Numer. Anal. Meth. Geomech., 27, 705-732.

22) Pande, G. N. and Sharma, K. G. (1983): Multilaminate model of clays-a numerical evaluation of the influence of rotation of principal stress axes, International Journal of Numerical and Analytical Methods in Geomechanics, 7(4), 397-418.

23) Pietruszczak, S. and Mroz, Z. (2000): Formulation of anisotropic failure criteria incorporating a microstructure tensor, Computer and Geotechnics, 26, 105-112.

24) Pietruszczak, S. and Mroz, Z. (2001): On failure criteria for anisotropic cohesive-frictional materials, Int. J. Numer. Anal. Math. Geomech., 25, 509-524.

25) Pietruszczak, S. and Pande, G. N. (2001): Description of soil anisotropy based on multilaminate framework, Int. J. Numer. Anal. Math. Geomech., 25, 197-206.

26) Rouainia, M. and Muir Wood, D. (2000): A kinematic hardening constitutive model for natural clays with loss of structure, Géotechnique, 50(2), 153-164.

27) Rowe, P. W. (1962): The stress-dilatancy relation for static equilibrium of an assembly of particles in contact, Proc. Royal Society of London, Mathematical and Physical Sciences, 269(Series A), 500-557.

28) Saihi, F., Leroueil, S., La Rochelle, P. and French, I. (2002): Behaviour of the stiff and sensitive Saint-Jean-Vianney clay in intact, destructured, and remoulded conditions, Can. Geotech. J., 39, $1075-1087$.

29) Scharinger, F. (2007): A multilaminate model for soil incorporating small strain stiffness, PhD Thesis, Gruppe Geotechnik Graz, Heft 31, Graz University of Technology, Austria.

30) Schweiger, H. F., Wiltafsky, C., Scharinger, F. and Galavi, V. (2009): A multilaminate framework for modelling induced and inherent anisotropy of soils, Géotechnique, 59(2), 87-101.

31) Søreide, O. K., Nordal, S. and Bonnier, P. G. (2002): An implicit friction hardening model for soil materials, Proc. 5th European Conference on Numerical Methods in Geotechnical Engineering (NUMGE) (ed. by Mestat), Paris, France, 155-161, Paris, Presses de l'ENPC/LCPC.

32) Taylor, G. I. (1938): Plastic strain in metals, Journal of the Institute of Metals, 62, 307-324, Reprinted in: The Scientific Papers of G. I. Taylor 1, 1958, Cambridge University Press, Cambridge, UK.

33) Wiltafsky, Ch. (2003): A multilaminate model for normally consolidated clay, $P h D$ Thesis, Gruppe Geotechnik Graz, Heft 18, Graz University of Technology, Austria. 